\title{
Relationships Between Access to Mobile Devices, Student Self-Directed Learning, and Achievement
}

\section{Scott R. Bartholomew, Ed Reeve, Raymond Veon, Wade Goodridge, Victor Lee, \& Louis Nadelson}

\begin{abstract}
Today's students are growing up in a world of constant connectivity, instant information, and ever-changing technological advancements. The increasingly ubiquitous nature of mobile devices among $\mathrm{K}-12$ students has led many to argue for and against the inclusion of these devices in K-12 classrooms. Arguments in favor cite instant access to information and collaboration with others as positive affordances that enable student self-directed learning.

In this study, 706 middle school students from 18 technology and engineering education classes worked in groups of 2-3 to complete an openended engineering design challenge. Students completed design portfolios and constructed prototypes in response to the design challenge. Classes were divided with some allowing access to mobile devices during the study and others not allowing access. Additionally, randomly assigned classes completed the design portfolio electronically, and others completed the portfolio on paper. Final student portfolios and products were assessed and assigned a rank order using a method of assessment called adaptive comparative judgment. Thirty student interviews were conducted as well as 6 teacher interviews. Statistical analyses between student access, portfolio type, student self-directed learning, and student achievement were conducted. Findings showed that student self-directed learning was independent of mobile device access during the study. Mobile device access was significantly correlated with higher student scores on the design portfolio, but mobile device access was independent of student scores on design products.
\end{abstract}

Keywords: Mobile devices, self-directed learning, middle school, technology and engineering

\section{Need}

Today's K-12 students, sometimes called "digital natives" (Prensky, 2001), are growing up in a world connected through technology. They are expected to be part of a global society that is linked through technology and to possess skills that will enable them to excel and continue as life-long learners (Johnson, Adams, \& Cummins, 2012; Prensky, 2007; Tulagan, 2013; West, 2013). Today's students often have more computing power in their personal mobile devices than their parents had during their educational years (Lenhart et al., 2015). A recent study from the Pew Research Center (Lenhart et al., 2015) 
found that " $73 \%$ of [American] teens have access to smartphones" (p. 5) and that " $92 \%$ of teens report going online daily-including $24 \%$ who say they go online 'almost constantly"' (p. 2).

Leveraging mobile devices to positively impact student achievement and self-directed learning, as well as the potential pitfalls associated with mobile devices in the classroom, has been a topic of recent discussion (Elder, 2009; Johnson, Adams, \& Haywood, 2011; Lloyd, 2010; O’Bannon \& Thomas, 2015; Quillen, 2010; Schenker, 2009; Shuler, 2009). However, the possibility of utilizing mobile devices to enhance student self-directed learning has not been explored.

Self-directed learning, a process in which individuals take the initiative to diagnose their own learning needs, identify resources for learning, and then evaluate their own learning (Knowles, 1975), is becoming increasingly relevant in today's educational landscape (Mitchell, 2014). There is a potential for mobile devices to facilitate self-directed learning. As Fahnoe and Mishra (2013) noted, opportunities for learners to be self-directed are often experienced with, and as a result of, technology.

\section{Purpose}

The purpose of this study was to determine what effect, if any, the use of mobile devices (e.g., iPad or smartphone) had on student self-directed learning and achievement in a middle school technology and engineering education (TEE) classroom during an open-ended engineering design activity. The findings from this research may benefit school administrators, teachers, parents, and students as the ongoing debate regarding the inclusion of mobile devices in the classroom continues. On a larger scale, the purpose of the study was to inform policy and decision makers as the face of education continues to change and evolve with the rapid advancements in technology. Mobile devices are one example of a potentially educational technology - an addition to the classroom that may facilitate learning and improve performance (Januszewski \& Molenda, 2008). The two research questions that guided this study were:

1. What relationship, if any, exists between middle school student access to mobile devices and student self-directed learning?

2. What relationship, if any, exists between middle school student access to mobile devices and student achievement on an open-ended design problem?

Although this study specifically looked at the influence of access to mobile devices on student self-directed learning and achievement, it should be noted that the findings of this study should not necessarily be confined to mobile devices. Mobile devices most directly offer the added benefit to students of access to information in real time, communication, and other functionalities. The findings from this study can be used to inform current thinking and inquiry regarding the place, use, and implementation of mobile devices. On a larger 
scale, these findings can be used as another resource in the debate surrounding personal access to the Internet, communication, and other functionalities in public schools.

\section{Self-Directed Learning}

Self-directed learning has been identified as a key 21 st century skill required for students to succeed (Fahnoe \& Mishra, 2013; Partnership for 21st Century Learning, 2015; Zsiga \& Webster, 2007). However, the majority of current research related to self-directed learning is about adult learners not $\mathrm{K}-12$ students (Fahnoe \& Mishra, 2013; Liu et al., 2014). Self-directed learning combines an understanding of what is not known with an understanding of what activities need to be undertaken in order to obtain the needed knowledge (Van Deur, 2004). Self-directed learning includes "self-managing, self-monitoring, and self-modifying capabilities [, which] . . . characterize[s] peak performers in all walks of life" (Costa \& Kallick, 2004, p. 52).

Self-directed learning has been identified as positively correlated with numerous characteristics, including GPA, openness, conscientiousness, emotional stability, extraversion, optimism, career-decidedness, work drive, life satisfaction, and self-actualization (Lounsbury, Levy, Park, Gibson, \& Smith, 2009). In one study, Fahnoe and Mishra (2013) examined sixth graders' selfdirected learning as it corresponded with technology use. Utilizing the SelfDirected Learning with Technology Scale (SDLTS; Teo et al., 2010), Fahnoe and Mishra (2013) reported that students in the technology-rich environment were statistically significantly more self-directed in their learning than their classmates in the traditional classroom, suggesting that technology carries with it the possibility of increasing and encouraging self-directed learning in $\mathrm{K}-12$ students.

In their article "Students' Perceptions of Self-Directed Learning and Collaborative Learning With and Without Technology," Lee, Tsai, Chai, and Koht (2014) found "that students who reportedly engaged in SDL [self-directed learning] and CL [collaborative learning] in face-to-face contexts also engaged in these forms of learning in technology-supported contexts" (p. 425), suggesting that self-directed learning practices may occur independently of the presence of technology. Exploring the influence of technology on the selfdirected learning practices of students was one goal of this study.

\section{Mobile Devices in K-12 Education}

Literature related to mobile devices spans a variety of settings, devices, and definitions. This article focuses on mobile devices and mobile learning in K-12 classrooms and used Traxler's (2005) definition of mobile learning: "any educational provision where the sole or dominant technology is a handheld or palmtop device" (p. 265). Additionally, this study utilized Kim, Holmes, and Mims' (2005) definition for mobile wireless technology (or mobile devices): 
"technology that provides continuous accessibility to users anytime, anywhere without using a wire or cable to connect to networks (like the internet), transmit data or communicate with others" (p. 55). For this study, the two identified definitions were combined to define mobile learning with the inclusion of mobile devices: "any educational provision where the sole or dominant technology is a handheld or palmtop device" (Traxler, 2005, p. 265) "that provides continuous accessibility to users anytime, anywhere, and without using a wire or cable to connect to networks (like the Internet), transmit data, or communicate with others" (Kim, Holmes, \& Mims, 2005, p 55).

Despite the rapid increases in mobile devices, mobile learning, and educational technology opportunities, research related to mobile devices in $\mathrm{K}-$ 12 settings is limited in scope (Cheung \& Hew, 2009; Hwang \& Tsai, 2011; Liu et al., 2014; Sutton, 2011; Wan, 2011). Although the impacts of mobile devices in K-12 classrooms are relatively unclear (Cheung \& Hew, 2009; Hwang \& Tsai, 2011; Liu et al., 2014; Sutton, 2011; Wan, 2011), there have been recent discernable efforts at implementing more "mobile friendly" policies and incorporating mobile devices into student learning experiences (Hwang \& Tsai, 2011; Liu et al., 2014; Lloyd, 2010; Quillen, 2010; Schenker, 2009; Shuler, 2009). The benefits of including mobile devices in $\mathrm{K}-12$ classrooms seem to center around student access to information, others, and technology (Lenhart et al., 2015; Prensky, 2007; Robledo, 2012; Shuler, 2009; West, 2013).

Interestingly, Mentzer (2011) showed that access to information (i.e., the Internet) did not improve student designs in an open-ended engineering design challenge when compared with other students without access. Relatedly, Pieper and Mentzer (2013) found that students with access to the Internet during an open-ended design challenge spent significantly more time accessing information than their peers without Internet access; however, this additional time was not always productive or impactful. This study aimed to add additional insight to the question of whether or not access to mobile devices, and in turn information, will be impactful on student learning in open-ended engineering design challenge settings.

\section{Adaptive Comparative Judgment}

In this study, the adaptive comparative judgment (ACJ) method was used to assess student product and portfolio performance. ACJ is a relatively new form of assessment, originating in the United Kingdom, and this is the first time that it has been used in a middle school research study in the United States. ACJ was developed through work by Alastair Pollitt and Richard Kimbell (see Pollitt, 2004, 2007, 2012 and Kimbell, 2007, 2012) and relies on comparisons rather than rubrics or scores for assessing student work. ACJ, based on Thurstone's law of comparative judgment (Thurstone, 1927), is a form of assessment in which judges are presented with two different artifacts of student work (in the case of this research, the judges viewed two design portfolios or two student 
products). Each judge is not asked to grade either of the artifacts but rather to simply make a holistic judgment about which artifact is better based on a provided rubric and their own professional opinion. This process is repeated a number of times until a rank-order is produced for the artifacts viewed by the judges.

Arguing in favor of this form of assessment, Pollitt (2004) and Kimbell (2012) point out that although current trends in education often favor rubrics, assessment of any kind ultimately involves the comparison of one thing to another.

All judgements are relative. When we try to judge a performance against grade descriptors we are imagining or remembering other performances and comparing the new performance to them. (Pollitt, 2004, p. 6)

Following the theoretical development of the ACJ process, a grading engine was commercialized by TAG Assessment under the name CompareAssess. Using a complex algorithm, which has been validated repeatedly and used on thousands of student artifacts (Pollitt, 2004, 2012), CompareAssess combines rankings from a panel of judges to assign a final rank order to each artifact. In the CompareAssess engine, each artifact is compared with other artifacts by randomly assigned graders until a specified reliability requirement has been met. The reliability obtained is best understood as the judge consistency coefficientsimilar to an inter-rater reliability level (Pollitt, 2015) - and this method of assessment has repeatedly demonstrated more reliability and validity than traditional methods of assessing student work (Kimbell 2012; Pollitt, 2004, 2007, 2012).

An additional point mentioned in the ACJ literature relates to the method's validity; ACJ results were compared with ranking results through traditional methods, and the resulting value of $R^{2}$ was 0.81 , corresponding to a correlation of 0.90 (Kimbell, Wheeler, Miller, \& Pollitt, 2007). These findings further suggest that the ACJ method of scoring is valid and will produce highly correlated results to traditional marking.

Interestingly, although ACJ is not widely used in the United States, the ACJ method of assessment shares some similarities to other innovative assessment techniques being piloted. Denson, Buelin, Lammi, and D'Amico (2015) recently published their work on developing a creativity assessment that makes use of an online platform for viewing and rating pieces of student work. Although this method did not use ACJ, it had other functions similar to CompareAssess and demonstrates a larger interest in alternative and more effective methods of assessment. 


\section{Methodology: Mixed-Method, Quasi-Experimental Study}

\section{Pilot Study}

Following Internal Review Board approval from the participating schools and the university, a pilot study was undertaken at a local middle school with two classes (the Exploring Technology class for seventh and eighth grade students). Each class received the same instruction and completed identical design challenges. One class completed the design portfolio on paper without access to mobile devices, and the other had access to mobile devices and completed the same design portfolio using an iPad app for portfolio creation entitled LiveAssess. LiveAssess was developed concurrent to the ACJ assessment engine through the efforts of Kimbell (2007) and similarly commercialized by TAG Assessments. The purpose of the pilot was to experiment with the research process, instruments, teacher pacing guide, and design challenge. During the pilot study, the researcher took copious notes regarding minor tweaks, language changes, and areas of confusion for the participating students. These notes, in addition to student comments regarding possible improvements (as gathered through post-pilot student questionnaires), were all used to revise the study prior to full implementation.

\section{Research Design}

Implementation of the full study took place in a large suburban school district in the western United States. This large school district is one of the 50 largest school districts in the United States with a primarily suburban middleclass population ( $16 \%$ free or reduced-price lunch). A total of six teachers were recruited for the study based on willingness to participate and possessing similar characteristics (teacher license level, similar years of teaching, similar classes taught, similar school facilities, and recommendation from the district TEE coordinator). Each teacher agreed to implement the study in at least two sections of the Exploring Technology class, an introductory TEE course for seventh and eighth graders. A total of 706 students were included in the study, which required five class periods (90-minute class periods every other day for 2 weeks). A total of 18 classes of the Exploring Technology course from the six teachers formed the population of the study. Two teachers used paper portfolios with their classes, and four teachers used iPads to complete the portfolios via the LiveAssess app. Four randomly assigned teachers (i.e., one paper-based portfolio, three iPad-based portfolio) were instructed to allow ubiquitous mobile device access, and the other two teachers (one paper-based portfolio, one iPadbased portfolio) were instructed to prohibit this access during the unit. The counter-balanced nature of the access and portfolio medium was undertaken in an effort to highlight possible problematic variables related to the dependent measures. 
Teachers were trained prior to the study in a 2-hour training session conducted by the researcher during which teachers were provided with paper and electronic access to all study and training materials. Teacher compliance and fidelity to study measures and to the provided teacher script were monitored through daily observations by the researcher and by means of responses to qualitative interviews at the conclusion of the study.

Students began the study by completing a pre-study questionnaire. This questionnaire included demographic questions, inquiries regarding their use and comfort with technology from the Digital Natives Assessment Scale (DNAS; Teo, 2013), and questions adapted from the Self-Directed Learning with Technology Scale (SDLTS; Teo et al., 2010). Following the pre-study questionnaire, students received instruction related to mobile device use, digital citizenship, and the engineering design process. Students were then placed in groups of 2-3 to complete an open-ended engineering design challenge. This challenge involved the designing of a new container or dispenser for distributing pills to patients in specified quantities and at prescribed times (see similar examples in Kimbell, 2007, 2012). Students designed the product for a specific user: an elderly individual who enjoys traveling internationally.

Initially, groups of students were provided with a "handling collection" consisting of materials chosen to stimulate idea generation and creativity (e.g., zippers, ties, string, plastic, and clay). Students were also shown pictures of pill holders and containers as well as the student creations from the pilot study. Following this brainstorming activity, students returned the materials in the "handling collection" and were provided with new materials from the "modeling collection" that was used to construct a solution to the design problem. Following prompts from their teachers, students filled out a design portfolio (either on paper or electronically) throughout the design challenge. The overall progression through this activity was managed by means of a provided teacher script that instructed teachers when to prompt students to complete a portion of their portfolio and when to move to a new portion of the lesson. The design portfolio was loosely influenced by similar portfolios used in Kimbell's research $(2007,2012)$ and was crafted to help the students display their progress through the design process.

Students worked on their designs and portfolios for four class periods and on the final day (Day 5), students turned in their portfolios and products and completed a post-study questionnaire. Teachers identified five students for the researcher to interview: two "high-performing" students, two "low-performing" students, and one "average-performing" student. The researcher conducted a semi-structured qualitative interview with these students and asked them questions related to self-directed learning, mobile devices, engineering design, and their experience with the study. Teachers were also interviewed and asked similar questions in an effort to further explore, clarify, and highlight the findings from the study. 


\section{Mixed-Method Data Collection}

Following the completion of the study, all the student products were collected, and a digital picture was taken of each one, resulting in 175 images of student design products. These pictures were uploaded to the CompareAssess ACJ engine for later use. Each paper portfolio was also "digitized" using a scanner and iPad to record student responses from the paper portfolios into electronic versions via the LiveAssess app. These were also added to the CompareAssess engine. Data responses to the pre- and post-study questionnaires were conditioned and matched, resulting in a pre-study, post-study, and combined data set for later analysis.

Student and teacher responses to qualitative interviews were transcribed and analyzed using descriptive and thematic coding following recommendations by Saldaña (2013). In the first step of this process, the transcriptions were analyzed, and several words that described the contents of the response were identified. The second step in the process involved a second review of the transcribed responses in which the descriptive responses were analyzed for general ideas and themes. In the third step, the identified themes and ideas were synthesized into overarching themes for each response. These themes were checked for triangulation with topics relevant to the study (e.g., mobile devices, self-directed learning, and open-ended problems). Following the quantitative analyses, the resulting final qualitative themes were used to clarify, expand, and inform the general findings from the quantitative portion of the study as well as highlighting future areas of research deserving exploration. Representative phrases and illuminating remarks from the student and teacher responses were included as illustrative examples of the overall findings.

A panel of five graders was formed, which included a Technology and Engineering Education professor, an Engineering Education Professor, an Art and Design Professor, a former middle-school teacher, and a graduate student in Technology and Engineering Education. The panel of graders was trained on the CompareAssess software and discussed the grading procedure together prior to completing judgments. Initially, each grader was given a login to the CompareAssess online judging platform and was asked to grade 20-30 portfolios and student products. Following this, an additional meeting was held to ensure a unified direction in judgment. Judges were asked to complete additional judgments up to 175 judgments of portfolios and 175 judgments of products, which resulted in a reliability coefficient of $r=.943$ for students products and $r=.934$ for student portfolios. Twenty additional judgments for portfolios and 20 more judgments for products were completed by each judge, which increased the reliability to $r=.959$ for student products and $r=.972$ for student portfolios. The result was a rank-order for student products and portfolios that was added to the statistical data set for later analysis.

Prior to analyses, regression diagnostics, including linearity, homoscedasticity, normality of residuals, uncorrelated error, mean 
independence, and normally distributed error, were conducted to ensure that the proper assumptions of were met for the statistical tests. It was determined that each of the tests was satisfied and that the assumptions were met. Following this, all quantitative data were analyzed using a variety of statistical procedures, including $t$-test, ANOVA, ANCOVA, correlation, and regression.

\section{Quantitative Findings}

The quantitative findings from the study were taken from three different sources: the pre-study questionnaire $(n=555)$, the post-study questionnaire $(n=$ $458)$, and the matched questionnaire $(n=221)$ containing student pre- and poststudy matched responses. The large decrease in $n$-size between the pre-study questionnaire and the matched questionnaire was due mainly to student error in entering identical unique identifiers on both the pre- and the post-study questionnaires. In order to ensure comparability between the data, independent samples $t$-tests were computed comparing the pre-study data with the combined data set on the following measures to test for significant differences: pre-study SDLTS score, DNAS score, average grades, average time spent with technology, average mobile device use, and average mobile device skill. The only test that revealed a significant difference between the pre-study data set and the combined data set was for average grades, $F(772)=6.13, p=.023$. A follow-up independent samples $t$-test, which compared the grades in TEE classes across the groups, did not return significant results $(p=.17)$. These tests demonstrate that in all tested cases, with the exception of average grades, the students in the combined data set were not significantly different from the total $n$ contained in the pre-study data set. It was thus concluded that, although not equal, the combined data set is comparable, representative, and suitable for use in further data analyses

\section{Self-Directed Learning Findings}

A simple linear regression was calculated to predict student self-directed learning (post-study questionnaire score) based on demographic variables (age, grades in all classes, grades in TEE classes, computer and mobile device access, time spent with technology, and pre-study SDLTS score). Upon initial investigation, it was shown that not all predictors were significant to student post-study SDLTS score. Non-significant factors were removed case by case until only significant factors were contained in the regression. This resulted in a significant regression equation $(F(2,218)=26.26, p<.001)$, with an adjusted $R^{2}$ of .19, and two significant predictors of student score on the post-study SDLTS assessment: average mobile device skill level and computer access and use at school (see Table 1). Student post-study SDLTS score is represented by $2.94+.40$ (average mobile device skill level) - . 18(computer access and use at school), suggesting a positive correlation between average mobile device skill 
level in students and self-directed learning and a negative correlation between computer access and use at school and student self-directed learning.

Table 1

Regression Equation Results for Student Demographic Information and Poststudy SDLTS Score

\begin{tabular}{lcccc}
\hline \multicolumn{1}{c}{ Variable } & Coefficient $B$ & $p$-value & $t$ & $r$ \\
\hline $\begin{array}{l}\text { Computer access at } \\
\text { school }\end{array}$ & -.07 & $p=.003$ & -3.02 & -.18 \\
$\begin{array}{l}\text { Mobile device skill } \\
\text { level }\end{array}$ & .29 & $p<.001$ & 6.61 & .40 \\
\hline
\end{tabular}

A paired-samples $t$-test was used to determine if there was a significant difference in the student SDLTS pre- and post-study questionnaires. The results evidenced a significant difference in student pre-study $(M=3.61, S D=.54)$ and post-study $(M=3.79, \mathrm{SD}=.57)$ scores, $t=6.521, p<.001, d=-.44$, indicating that students were more self-directed following the study.

It was anticipated that student scores on the DNAS would be predictive of their post-study SDLTS scores. A correlational analysis revealed a significant correlation $(p<.001)$ in the positive direction between student DNAS and student pre-study SDLTS as well as student post-study SDLTS scores (Table 2), suggesting that higher levels of "digital nativeness" among students corresponded with higher self-directed learning.

Table 2

Correlation for Student DNAS Scores and Student Pre- and Post-Study SDLTS Scores

\begin{tabular}{lcc}
\hline & Pre-SDLTS score & Post-SDLTS score \\
\hline Pearson correlation & .40 & .31 \\
Sig. (2-tailed) & .00 & .00 \\
$n$ & 221 & 221 \\
\hline
\end{tabular}

Different mediums were purposely utilized for student design portfolios as part of the counter-balanced study format. In order to separate significance based solely off the difference in portfolio medium, tests were run to determine the impact of paper or electronic portfolios on student post-study SDLTS score. Utilizing an ANCOVA, with student pre-study SDLTS score as the covariate, portfolio type and student post-study SDLTS were analyzed. The resulting $p$ value was not statistically significant $(p=.132$ ), suggesting that student post- 
study SDLTS score was independent of their assigned portfolio creation medium.

Using ANCOVA statistical techniques, analyses were conducted examining the relationship between student access to mobile devices and student post-study SDLTS score, using students' pre-study SDLTS score as a covariate. The resulting value, $p=.816$, was not significant, suggesting that student scores on self-directedness in learning with technology are independent of access to mobile devices.

A simple bivariate correlation test was conducted to look at the relationship between student comfort level with open-ended design problems and post-study SDLTS score. This reflected a significant correlation $(p<.001)$ in the positive direction, suggesting that higher comfort levels with open-ended design problems are correlated with higher post-study SDLTS scores.

Using a simple correlation test, the relationship between student comfort level in working with groups and student post-study SDLTS scores was found to be significant $(p<.001)$ and positive, suggesting that higher comfort in working in groups was correlated with higher post-study SDLTS scores.

\section{Achievement Findings}

Student achievement was measured in two ways as part of this study: student rank score on their group portfolio and student rank score on their group product (created during the design challenge). Possible relationships between student final scores and other potential predictors were explored using a variety of statistical methods.

Using correlation statistical analyses, the relationships between student group portfolio score (rank) and student group product score (rank) were identified. Table 3 outlines the relationships between student portfolio rank score and demographics with several significant $(p<.05)$ correlations (age, grades, time with technology, skill with mobile devices, and access to mobile devices). When compared, the relationship between student product rank score and demographics demonstrated that age was the only significant correlation $(p$ $=.05)$. 
Table 3

Student Demographics Measures and Student Portfolio Rank Score

\begin{tabular}{lccc}
\hline \multicolumn{1}{c}{ Student portfolio rank } & Spearman correlation & Sig. (2-tailed) & $n$ \\
\hline Student age & .16 & .02 & 221 \\
Grades in average (all classes) & .13 & .05 & 220 \\
Grades on average (TEE only) & -.02 & .83 & 221 \\
Average time using technology & .27 & .00 & 214 \\
Average mobile device use & .05 & .45 & 221 \\
Skill level with mobile devices & .15 & .02 & 221 \\
DNAS score & .12 & .08 & 221 \\
Prestudy SDLTS score & -.07 & .33 & 221 \\
Computer access (home) and use & .05 & .50 & 221 \\
Computer access (school) and use & .09 & .17 & 218 \\
Mobile device access (home) and use & .27 & .00 & 219 \\
Mobile device access (school) and use & .24 & .00 & 219 \\
\hline
\end{tabular}

A set of simple correlation tests revealed that the correlation between student pre-study SDLTS score and their portfolio rank score was not significant $(r=-.07, p=.33)$. The correlation between student pre-study SDLTS score and their product rank score was also not significant $(r=-.05, p=.48)$.

A correlation was computed for student self-directed learning, as measured on the post-study SDLTS, and student rank portfolio score. A correlation was also computer for student self-directed learning, as measured on the post-study SDLTS, and student rank product score. Neither relationship returned a significant value.

Looking at correlation tests, the correlation between student DNAS scores and their product rank score was not significant $(r=-.04, p=.54)$. The correlation between student DNAS scores and their portfolio rank score approached significance $(r=.12, p=.08)$ but was not significant.

Using an independent samples $t$-test, the impact of portfolio type on student achievement (both portfolio and product rank scores) was analyzed. There was a significant difference in student product scores between paper $(M=73.93, S D=$ $52.22)$ and electronic portfolios $(M=97.71, S D=49.63) ; t(455)=-4.83, p<$ .001 . There was also a significant difference in student portfolio scores between paper $(M=68.83, S D=39.46)$ and electronic portfolios $(M=96.58, S D=$ 53.43); $t(454)=-5.84, p<.001$. It is important to note that the scores for the portfolios and the products are rank scores, so a lower rank is deemed of higher quality than a higher rank.

Using an independent samples $t$-test, the impact of mobile devices on student achievement (both portfolio and product rank scores) was analyzed. There was a significant difference in student portfolio scores between those with 
access to mobile devices $(M=81.65, S D=52.07)$ and those without access to mobile devices $(M=101.29, S D=42.52) ; t(454)=-3.62, p<.001$. However, there was not a significant difference in student product scores between those with access to mobile devices $(M=90.20, S D=52.82)$ and those without access to mobile devices $(M=85.60, S D=48.60) ; t(455)=.816, p=.415$.

A one-way ANOVA was computed to assess the impact of the teacher on student achievement scores for the portfolio. The results were significant $(F=$ $37.70, p<.001$ ), and LSD post hoc analyses were computed to further explore the difference between teacher groups (see Table 4).

Table 4

Post Hoc Analysis of Differences in Student Product Rank by Teacher

\begin{tabular}{ccccccc}
\hline Teacher $(n, M, S D)$ & 1 & 2 & 3 & 4 & 5 & 6 \\
\hline Teacher $1(85,77.99,47.39)$ & .00 & .00 & .35 & .00 & .79 \\
Teacher 2 $(84,107.17,51.11)$ & & .94 & .00 & .62 & .00 \\
Teacher 3 $(69,106.54,48.26)$ & & & .00 & .69 & .00 \\
Teacher 4 $(59,70.10,47.20)$ & & & & .00 & .46 \\
Teacher 5 $(53,102.85,44.51)$ & & & & & .00 \\
Teacher 6 $(107,76.05,54.89)$ & & & & & \\
\hline
\end{tabular}

A separate one-way ANOVA was computed to assess the impact of the teacher on student achievement scores for the product, which also returned significant results $(F=8.77, p<.001)$. This necessitated LSD post hoc analyses to further explore the difference between teacher groups (see Table 5). Both Tables 4 and 5 highlight significant differences in students achievement based on teacher.

Table 5

Post Hoc Analysis of Differences in Student Portfolio Rank by Teacher

\begin{tabular}{lllllll}
\hline Teacher $(n, M, S D)$ & 1 & 2 & 3 & 4 & 5 & 6 \\
\hline Teacher $1(84,64.26,48.98)$ & .00 & .00 & .00 & .00 & .12 \\
Teacher 2 $(84,130.55,44.32)$ & & .00 & .00 & .00 & .00 \\
Teacher 3 $(69,85.20,45.78)$ & & & & .22 & .00 & .00 \\
Teacher 4 $(59,94.58,36.23)$ & & & & & .08 & .00 \\
Teacher 5 $(53,108.75,47.83)$ & & & & & .00 \\
Teacher 6 $(107,86.47,50.56)$ & & & & &
\end{tabular}




\section{Qualitative Findings}

The final themes emerging from the student and teacher interviews were used to triangulate, clarify, and expand the quantitative findings resulting from the analysis of the student questionnaires and final rank order of the products and portfolios. The themes, along with representative responses, are included here.

\section{Self-Directed Learning}

Student and teacher comments related to self-directed learning revolved around the necessity of student choice for self-directed learning to occur. Two students commented on student choice in defining self-directed learning.

[Self-directed learning is] something that you, like go and do yourself, like you are interested in it, you want to go and figure out what this thing is ... or how something works.

[Self-directed learning is] somebody actually choosing what they have to do and what they want to do in their education.

One teacher comment also highlighted the student initiative and choice involved with self-directed learning.

Self-directed learning is where a student takes their own personal initiative to take the supplies that I've provided and also the knowledge that I have provided that they need, and of their own knowledge and their own supplies - based off of rules and I guess regulations, based off of our assignments or whatever - to create a learning environment where they are benefitted.

\section{Mobile Devices}

Teachers and students responded to questions regarding the potential benefits and challenges of mobile devices in $\mathrm{K}-12$ education. Their responses themed around (a) mobile devices being enablers or both positive and negative behavior, (b) mobile devices being regulated by strict rules and monitoring, and (c) classroom norms acting in opposition to mobile device integration. Examples of student comments related to the enabling nature include the following.

[Mobile devices] help, because you can look . . . like if you want to learn something, like if you were trying to teach yourself how to play the guitar or something you could look up videos online of how to do it.

Well it just matters on the kid pretty much. I think that [mobile devices] would help most kids, but some kids are just there to get the grade and to 
dink off with it and ruin the privileges. It would help them because like, they, oh I feel familiar with this - I know what to do, I know where to go.

I think [mobile devices] would help some kids, but some kids would just play on them, and then, maybe look up a few things ... I would use mine for, uh, learning because I don't really like being on social media, but I don't know about other people very well, I just see a lot of people on Instagram during lunch. So ... I'm not really, out to using it the same way as other people.

Students identified strict rules, regulations, and monitoring as both the reality and a necessity for mobile devices in $\mathrm{K}-12$ classrooms. Student comments also centered on different areas where mobile devices were allowed and other areas where mobile devices were prohibited. Example student responses include the following.

I think [mobile devices] would ... help, but there would have to be restrictions, 'cuz if kids were just playing on their phones, they wouldn't be learning, and they wouldn't like, be paying attention to the teacher. So they wouldn't get the grade they want on their test, and, so, that would bring grades down, but like using them would in like, effective ways in schools, would bring them up.

In school [mobile devices] are allowed during class, if the teacher gives you permission, only if you are, like, working on an assignment or something. Um, they are allowed during lunch — private time — before and after school. Um, and like usually people just, like, use them to do, like, calculators or math, and stuff like that.

It all depends like what class, like [mobile devices] are not allowed in like, during class but some teachers like let you use them for like certain things if you don't know, like, how to like, spell something or like draw something then you're allowed to use them.

Teachers' comments were similarly themed to the student responses in regards to the need for rules and regulations in order for mobile devices to be successful in $\mathrm{K}-12$ classrooms. One example response illustrates this general consensus among teachers:

I think that [mobile devices in $\mathrm{K}-12$ classrooms] can be good in a monitored fashion, with activities like the one we did, or other experience design activities. It could be very valuable in the research and 
understanding what the actual problem is they're trying to solve and where it fits in the world of what the impact that decision or solution might have.

Regardless of permission to use mobile devices, the majority of students did not choose to use mobile devices regularly throughout the study. When asked about the reasons guiding the students' decision to use or not to use a mobile device during the study, teachers highlighted classroom norms as a potential reason for students not using mobile device: Students and teachers were accustomed to a restriction on device use in class that prevailed despite permission to use the devices. One teacher remarked,

I had a couple kids looking on the iPad on the Internet. Honestly I was surprised that when we opened it up to the mobile devices more students didn't have their cell phones out. Most of them were just looking for images in [one] of the pill bottle folder things. But I was surprised at, I guess, the lack of using that device. Maybe it's because they're not used to using it in my classroom-I really don't know. The only thing I can think of is because it's the rule that you don't have your cell phone out in my class, I kind of felt like that was the norm.

\section{Summary of Findings}

For the middle-school students in this study, self-directed learning appeared to be related to student and environmental characteristics rather than access to specific technology tools. When analyzed, student self-directed learning was independent and even negatively correlated with access to some technology tools (e.g., mobile devices and computers), and student self-directedness in learning scores were independent of student portfolio type (paper vs. electronic). Taken together, these findings suggest that technology tools in and of themselves may not correspond with an increase in student self-directed learning and, in some cases, may be detrimental to student self-directed learning. These findings appear to align with Mentzer's (2011) research, which also concluded that access to information (i.e., the Internet via computers) did not significantly improve student designs.

Unlike technology tools, a variety of specific student and classroom environment characteristics did demonstrate significant relationships with student self-directed learning. Student characteristics that corresponded with higher levels of self-directedness in learners were: average skill in using mobile devices, higher "digital nativeness" scores, student familiarity with open-ended design problems, and student comfort level in working in groups. Responses in teacher interviews seem to concur with this. Teachers discussed how they perceived self-directed learning to be a product of external conditions such as: the presence of an open-ended problem, a task involving group work, or other classroom-environmental factors. 
Student achievement was identified through two separate student scores: student portfolio scores and student product scores. In qualitative interviews, the teachers and students were in agreement that mobile devices had the potential to improve students' achievement if used correctly.

A key finding is that teachers and portfolio medium (paper vs. electronic) were the most significant factors in student achievement. Students completing portfolios on paper produced significantly better portfolios and products than their counterparts who completed electronic portfolios. Despite the fact that all teachers in the study were comparable, there were significant differences in the final grades received by the students of each teacher, with the students of one teacher (Teacher 6) scoring significantly higher than the other students in the study. This teacher was assigned to complete the portfolios on paper, which may be a confounding factor resulting in the paper portfolios being ranked much higher than the electronic portfolios and this teacher's students outperforming the others. These findings align with other research demonstrating the significant impact of a teacher on their students above and beyond other factors (Darling-Hammond, 2000).

\section{Student Portfolios}

Student access to mobile devices was significantly correlated with higher study scores on the design portfolio. Average time spent with technology, student age, mobile device skill level, and mobile device access at home and school were also significantly correlated with higher scores. Student pre-study SDLTS and student post-study SDLTS scores were both independent of student portfolio score rank - an important finding suggesting that self-directed learning may not be indicative of student achievement, ability, and skill with the engineering design process despite its identification as a key skill for $21 \mathrm{st}$ century learners (Partnership for 21st Century Learning, 2015).

\section{Student Products}

Unlike the portfolio scores, the only significant correlation found between student product scores, aside from teacher and portfolio type, was student age. Older students tended to receive better scores on their design products. Student portfolio scores were not significantly correlated with pre- or post-study SDLTS, pre-study DNAS score, or access to mobile devices. Interestingly, the two teachers with the overall top-performing students (Teachers 4 and 6) had the youngest average students in their participating classes across the study. This emphasizes the strength of the impact made on students' achievement by their teacher.

\section{Other Observations}

Of particular interest, the researcher noticed that although many students were given access to mobile devices, students rarely used mobile devices during 
the product creation or the portfolio creation. Teachers echoed this sentiment during interviews and provided several conjectures for lack of mobile device usage, including: lack of need for mobile devices, the competition between computers and mobile devices, and classroom norms. Although students cited specific benefits of mobile devices in the interviews, the majority $(65.4 \%)$ of students who were given access to mobile devices during the study reported using mobile devices less than 30 minutes during class over the course of the entire study (over 360 minutes of class time). In the interviews, students mentioned that this activity was the "wrong type of problem" for using a mobile device. When asked for clarification, students commented that they were unsure how to use a mobile device to help them with an open-ended problem and were most comfortable using their mobile devices to answer factual single-answer problems. Student and teacher interview responses also themed around classroom norms: Although mobile devices were allowed, the previously established classroom norm (no mobile devices allowed) appeared to be highly influential on students' choices regarding mobile device use.

\section{Further Research and Analysis}

Using both the quantitative and qualitative findings from this study, the following recommendations and areas for further research and analysis were identified.

\section{Self-Directed Learning}

As noted, mobile devices did not make a significant impact on student selfdirected learning as measured by the SDLTS on the pre- or post-study questionnaires. However, several other student and classroom environment characteristics were positively correlated with self-directed learning in a significant way, including student skill in using mobile devices and student "digital nativeness." This suggests that teachers and schools should emphasize student skills in using and interacting with technology as a means of improving self-directed learning. If students can more effectively interact with different technologies (e.g., mobile devices, tablets, and computers), their opportunities and abilities for self-directed learning may also increase.

\section{Mobile Devices}

Although mobile devices did not significantly impact student self-directed learning in this study, mobile devices did correlate significantly with higher student achievement on the design portfolio. During student interviews, a theme that emerged with relation to mobile devices was the need for direct instruction regarding how, when, and where students should use mobile devices. Teachers can work through explicit instruction so those students understand how to use mobile devices and so that positive and appropriate uses of mobile devices become the new norm for their classroom. 


\section{Further Research}

Additional relationships between student mobile device access and factors outside of self-directed learning or achievement would shed further light on the debate over mobile devices in the classroom. The findings from this study are limited in scope to a relatively suburban, middle-class, homogeneous population within specific grade levels (seventh and eighth grade). Other research with different population groups, ages, or different locations could shed additional light on and provide valuable comparisons for the findings of this study. As teacher impact was highly significant in this study, it is recommended that additional studies of varying research designs be undertaken to explore supplementary data that examine specifically the impacts of teacher influence. Additionally, student gender was not collected during this study - this has been identified in other studies as significant (Reio \& Davis, 2005) and should be taken into account in future research efforts around student self-directed learning.

\section{Implications}

Granting access to mobile devices in middle school TEE classrooms during a STEM activity appears to have the potential to transform and improve student educational experiences. Although student self-directed learning was not significantly impacted in this study by access to mobile devices, aspects of student achievement showed positive correlations with access to mobile devices. In order for mobile devices to be impactful, teachers and students will need to work together to change the classroom norms relating to mobile device use, and teachers will need to model appropriate and effective mobile device use for their students.

In this study, student self-directed learning correlated more closely with student and classroom characteristics than it did with access to technology tools, suggesting a possible shift in the debate surrounding mobile device inclusion in classrooms from the actual tools to the learner and classroom characteristics. As previously shown (Darling-Hammond, 2000), the impact of a teacher on student achievement is significant: Students' final portfolio and product scores were more directly related to their teacher than any other variable. Focus on effective teacher habit identification and training should take precedence over technology tools and other classroom add-ons.

\section{References}

Costa, A. L., \& Kallick, B. (2004). Launching self-directed learners. Educational Leadership, 62(1), 51-55.

Cheung, W. S., \& Hew, K. F. (2009). A review of research methodologies used in studies on mobile handheld devices in K-12 and higher education settings. Australasian Journal of Educational Technology, 25(2), 153-183. doi:10.14742/ajet.1148 
Darling-Hammond, L. (2000). Teacher quality and student achievement: A review of state policy evidence. Educational Policy Analysis Archives, 8. doi:10.14507/epaa.v8n1.2000

Denson, C. D., Buelin, J. K., Lammi, M. D., \& D’Amico, S. (2015). Developing instrumentation for assessing creativity in engineering design. Journal of Technology Education, 27(1), 23-40. doi:10.21061/jte.v27il.a.2

Elder, J. (2009, October 29). OMG! Teachers say texting can be good for teens. Sauk Valley Media. Retrieved from http://www.saukvalley.com/2009/10/29/omg-teachers-say-texting-can-begood-for-teens/ap5xt6y/

Fahnoe, C. \& Mishra, P. (2013). Do 21st century learning environments support self-directed learning? Middle school students' response to an intentionally designed learning environment. In R. McBride \& M. Searson (Eds.), Proceedings of SITE 2013-Society for Information Technology \& Teacher Education International Conference 2013 (pp. 3131-3139). Chesapeake, VA: Association for the Advancement of Computing in Education.

Hwang, G.-J. \& Tsai, C.-C. (2011). Research trends in mobile and ubiquitous learning: A review of publications in selected journals from 2001 to 2010. British Journal of Educational Technology, 42(4), E65-E70. doi:10.1111/j.1467-8535.2011.01183.x

Januszewski, A., \& Molenda, M. (Eds.). (2008). Educational technology: A definition with commentary. New York, NY: Erlbaum.

Johnson, L., Adams, S., \& Cummins, M. (2012). NMC horizon report: 2012 higher education edition. Austin, TX: New Media Consortium. Retrieved from https://www.nmc.org/pdf/2012-horizon-report-HE.pdf

Johnson, L., Adams, S., \& Haywood, K. (2011). NMC horizon report: 2011 K12 edition. Austin, Texas: New Media Consortium. Retrieved from https://www.nmc.org/sites/default/files/pubs/1316810422/2011-HorizonReport-K12.pdf

Kim, S. H., Holmes, K., \& Mims, C. (2005). Mobile wireless technology use and implementation: Opening a dialogue on the new technologies in education. Techtrends: Linking Research and Practice to Improve Learning, 49(3), 54-64. doi:10.1007/BF02763647

Kimbell, R. (2007). E-assessment in project e-scape. Design and Technology Education: An International Journal, 12(2), 66-76. Retrieved from https://ojs.lboro.ac.uk/DATE/article/view/Journal_12.2_0707_RES6

Kimbell, R. (2012). Evolving project e-scape for national assessment. International Journal of Technology and Design Education 22(2), 135-155. doi:10.1007/s10798-011-9190-4

Kimbell, R., Wheeler, T., Miller, S., \& Pollitt, A. (2007). E-scape portfolio assessment phase 2 report. London, England: Technology Education Research Unit, Goldsmiths University of London. 
Knowles, M. S. (1975). Self-directed learning: A guide for learners and teachers. Englewood Cliffs, NJ: Cambridge Adult Education.

Lee, K., Tsai, P.-S., Chait, C. S., \& Koht, J. H. L. (2014). Students' perceptions of self-directed learning and collaborative learning with and without technology. Journal of Computer Assisted Learning, 30(5), 425-437. doi:10.1111/jcal.12055

Lenhart, A., Duggan, M., Perrin, A., Stepler, R., Rainie, L., \& Parker, K. (2015). Teens, social media \& technology overview 2015: Smartphones facilitate shifts in communication landscape for teens. Washington, DC: Pew Research Center. Retrieved from http://assets.pewresearch.org/wpcontent/uploads/sites/14/2015/04/PI_TeensandTech_Update2015_0409151. pdf

Liu, M., Scordino, R., Geurtz, R, Navarrete, C., Ko, Y., \& Lim, M. (2014). A look at research on mobile learning in K-12 education from 2007 to the present. Journal of Research on Technology in Education, 46(4), 325-372. doi:10.1080/15391523.2014.925681

Lloyd, J. R. (2010, August 16). Cell phones head to class. San Antonio Express News. Retrieved from http://www.mysanantonio.com/news/education/article/Cell-phones-head-toclass-780555.php

Lounsbury, J. W., Levy, J. J., Park, S.-H., Gibson, L. W., \& Smith, R. (2009). An investigation of the construct validity of the personality trait of selfdirected learning. Learning and Individual Differences, 19(4), 411-418. doi:10.1016/j.lindif.2009.03.001

Mentzer, N. (2011). Engineering design thinking and information gathering final report. Retrieved from http://ncete.org/flash/pdfs/Mentzer\%20Final\%20Report.pdf

Mitchell, L. (2014, March 14). Rise of the YouTube makeup artist: Nearly half of women use online tutorials. Express. Retrieved from: http://www.express.co.uk/life-style/style/464633/Pixiwoo-Lauren-CurtisFrozen-Nearly-half-of-women-copy-popular-online-makeup-tutorials

O’Bannon, B. W. \& Thomas, K. M. (2015). Mobile phones in the classroom: Preservice teachers answer the call. Computers \& Education, 85, 110-122. doi:10.1016/j.compedu.2015.02.010

Partnership for 21st Century Learning. (2015). P21 framework definitions. Retrieved from http://www.p21.org/storage/documents/docs/P21_Framework_Definitions_ New_Logo_2015.pdf

Pieper, J. \& Mentzer, N. (2013). High school students' use of paper-based and Internet-based information sources in the engineering design process. Journal of Technology Education, 24(2), 78-95. doi:10.21061/jte.v24i2.a.6 
Pollitt, A. (with Elliott, G., \& Ahmed, A.). (2004, June). Let's stop marking exams. Paper presented at the annual conference of the International Association for Educational Assessment, Philadelphia, PA.

Pollitt, A. (2007). Grading students' work. In Kimbell, R., Wheeler, T., Miller, S., and Pollitt, A., E-scape portfolio assessment phase 2 report (pp. ?-?). London, England: Technology Education Research Unit, Goldsmiths University of London.

Pollitt, A. (2012). The method of adaptive comparative judgement. Assessment in Education: Principles, Policy \& Practice, 19(3), 281-300. doi:10.1080/0969594X.2012.665354

Prensky, M. (2001). Digital natives, digital immigrants: Part 1. On the Horizon, 9(5), 1, 3-6. doi:10.1108/10748120110424816

Prensky, M. (2007). Changing paradigms. Educational Technology, 47(4), 64.

Quillen, I. (2010, October 15). Schools open doors to students' mobile devices. Education Week: Digital Directions. Retrieved from http://www.edweek.org/dd/articles/2010/10/20/01mobile.h04.html

Reio, T. G., Jr., \& Davis, W. (2005). Age and gender differences in self-directed learning readiness: A developmental perspective. International Journal of Self-Directed Learning, 2(1), 40-49. Retrieved from https://docs.wixstatic.com/ugd/dfdeaf_aabb3036f5594ce7ad25ca4edaa6264 a.pdf

Robledo, S. J. (2012). Mobile devices for learning: What you need to know. San Rafael, CA: Edutopia. Retrieved from http://www.edutopia.org/pdfs/guides/edutopia-mobile-learning-guide.pdf

Saldaña, J. (2013). The coding manual for qualitative researchers (2nd ed.). Thousand Oaks, CA: Sage.

Schenker, L. (2009, April 19). Schools embrace txt msg. The Salt Lake Tribune. Retrieved from http://archive.sltrib.com/story.php?ref=/news/ci_12179870

Shuler, C. (2009). Pockets of potential: Using mobile technologies to promote children's learning. New York, NY: The Joan Ganz Cooney Center at Sesame Workshop. Retrieved from http://www.joanganzcooneycenter.org/wpcontent/uploads/2010/03/pockets_of_potential_1_.pdf

Sutton, B. B. (2011, August 21). Mobile devices in the classroom: Stem stuff [Web log post]. Retrieved from http://www.edutopia.org/groups/sciencetechnology-engineering-mathematics-education/70218

Teo, T. (2013). An initial development and validation of a Digital Natives Assessment Scale (DNAS). Computers \& Education, 67, 51-57. 
Teo, T., Tan, S. C., Lee, C. B., Chai, C. S., Koh, J. H. L., Chen, W. L., \& Cheah, H. M. (2010). The self-directed learning with technology scale (SDLTS) for young students: An initial development and validation. Computers \& Education, 55(4), 1764-1771. doi:10.1016/j.compedu.2010.08.001

Thurstone, L. L. (1927). A law of comparative judgment. Psychological Review, 34(4), 273-286. doi:10.1037/h0070288

Traxler, J. (2005). Defining mobile learning. In P. Isaías, C. Borg, P. Kommers, \& P. Bonanno (Eds.), Proceedings of the 2005 IADIS International Conference on Mobile Learning (pp. 261-266). Qwara, Malta: IADIS Press.

Tulagan, B. (2013). Meet Generation Z: The second generation within the giant "Millennial" cohort [White paper]. Retrieved from http://rainmakerthinking.com/assets/uploads/2013/10/Gen-ZWhitepaper.pdf

Van Deur, P. (2004). Gifted primary students' knowledge of self-directed learning. International Education Journal, 4(4), 64-74. Retrieved from http://www.iejcomparative.org/data/volumes/v4n4.pdf

Wan, Y. (2011, November 4). Mobile learning [Memorandum]. Chicago, IL: Regional Educational Laboratory (REL) Midwest at American Institutes for Research. Retrieved from $\mathrm{ftp} / / / \mathrm{ftp}$. ode.state.oh.us/geodoc/Ohio_Digital_Learning/Mobile\%20Learnin g-ed_Final.pdf

West, D. M. (2013). Mobile learning: Transforming education, engaging students, and improving outcomes. Washington, DC: Center for Technology Innovation at Brookings. Retrieved from https://www.brookings.edu/wpcontent/uploads/2016/06/BrookingsMobileLearning_Final.pdf

Zsiga, P. L., \& Webster, M. (2007). Why should secondary educators be interested in self-directed learning? International Journal of Self-Directed Learning, 4(2), 58-68. Retrieved from https://docs.wixstatic.com/ugd/dfdeaf_2e28e194adcc4f109eb796db14d6b13 4.pdf

\section{About the Authors}

Scott R. Bartholomew (sbartho@purdue.edu) is Assistant Professor of Engineering/Technology Teacher Education at Purdue University.

Ed Reeve (ed.reeve@usu.edu) is Professor of Technology \& Engineering Education at Utah State University.

Raymond Veon (raymond.veon@usu.edu) is Assistant Dean for Arts Education at Utah State University.

Wade Goodridge (wade.goodridge@usu.edu) is Assistant Professor of Engineering Education at Utah State University.

Victor Lee (victor.lee@usu.edu) is Associate Professor of Instructional Technology and Learning Sciences at Utah State University.

Louis Nadelson (lnadelson@coloradomesa.edu) is Director of Sponsored Programs and Academic Research at Colorado Mesa University. 